\title{
Bhanupaka: A Green Process in the Preparation of an Indian Ayurvedic Medicine, Lauha Bhasma
}

\author{
Balaji Krishnamachary, ${ }^{1,2}$ Arun K. Purushothaman,, \\ Brindha Pemiah, ${ }^{1,2}$ Sridharan Krishnaswamy, ${ }^{1}$ Uma Maheswari Krishnan,,3 \\ Swaminathan Sethuraman, ${ }^{1,3}$ and Rajan K. Sekar ${ }^{1,3}$ \\ ${ }^{1}$ School of Chemical \& Biotechnology, SASTRA University, Thanjavur, Tamil Nadu 613 401, India \\ ${ }^{2}$ Centre for Advanced Research in Indian System of Medicine, SASTRA University, Thanjavur, Tamil Nadu 613 401, India \\ ${ }^{3}$ Centre for Nanotechnology \& Advanced Biomaterials, SASTRA University, Thanjavur, Tamil Nadu 613 401, India
}

Correspondence should be addressed to Rajan K. Sekar; ksrajan@chem.sastra.edu

Received 30 June 2012; Revised 21 December 2012; Accepted 22 December 2012

Academic Editor: Lorenzo Cerretani

Copyright (c) 2013 Balaji Krishnamachary et al. This is an open access article distributed under the Creative Commons Attribution License, which permits unrestricted use, distribution, and reproduction in any medium, provided the original work is properly cited.

\begin{abstract}
The use of lauha bhasma, a traditional Indian herbometallic preparation, is in vogue for centuries for the treatment of various ailments related to iron deficiency. The preparation of lauha bhasma requires strict adherence to time-consuming, well-practiced, multistage, and multistep procedures. One of the steps is the treatment of purified metallic ingredients with Triphala decoction (the aqueous extract of Indian gooseberry, Chebulic myrobalans, and Beleric myrobalans) in the presence of sunlight (Bhanupaka). The formation of metal complexes due to the reaction of the metallic ingredients with the constituents of Triphala decoction has been ascertained by FTIR spectroscopy and carbon, hydrogen, and nitrogen analyses. Our results demonstrate that Bhanupaka is an essential step in the preparation of lauha bhasma.
\end{abstract}

\section{Introduction}

Ayurveda is a traditional Indian system of medicine that has evolved during 5000 B.C. Bhasma is a class of drugs developed by Ayurvedic practitioners, who have formulated, practiced, and mastered various medicinal preparations. Ayurveda believes in systematically applying the knowledge about health and diseases in correcting the unbalanced states of humors [1]. Some of the unique features of Ayurveda include simple diagnostic methods, emphasis on prevention and cure of disease, use of materials available in nature for preparation, and openness to learning from other systems of medicine [1]. Bhasma is prepared from metallic and herbal ingredients and is also referred to as herbometallic preparations [2]. The practitioners of Ayurveda had wisdom to realize the importance of key metallic elements required in ensuring proper functioning of physiological systems. They had mastered the art of administering these elements in nontoxic, absorbable form through a series of meticulous physicochemical transformations achieved using various herbal and animal products.

Lauha bhasma is widely used for the treatment of anemia, hyperlipidemia, tuberculosis, urinary tract infections, obesity, and so forth [3]. The process flow diagram for the preparation of lauha bhasma is available [4], and the preparation involves samanya sodhana (general purification step), vishesha sodhana (special purification step), Bhanupaka (reaction under sunlight), sthalipaka (roasting of contents in iron vessel), and puta (calcination). These steps are believed to have a strong scientific basis. However, these have not been properly documented leading to quality control issues during the manufacturing process. Thus, the scientific rationale in the preparation of lauha bhasma needs to be explored and validated. 
Bhanupaka is a green process that utilizes Triphala decoction and natural reaction conditions to bring about transformations to the intermediate obtained after vishesha sodhana. Triphala decoction is an aqueous extract of the mixture of three dried fruits, namely, Terminalia chebula (Chebulic myrobalans), Terminalia belerica (Beleric myrobalans), and Phyllanthus emblica (Indian gooseberry). In our earlier work, morphological changes during Bhanupaka and a hypothesis for the possible role of sunlight and Triphala decoction were reported [4]. However, the hypothesis was tested by experiments on the reaction between iron (III) chloride and Triphala decoction under ultraviolet exposure for a short period of time, followed by KCNS test of the filtered liquid. The aim of the present work is to investigate the chemical transformations imparted to the intermediate obtained after vishesha sodhana during the Bhanupakastep, by chemical characterization using various analytical techniques.

\section{Materials and Methods}

2.1. Preparation of Intermediates. Kanta Lauha (Iron powder) has been used as the raw material for the preparation of lauha bhasma. The mass percentage of iron was found to be greater than $98 \%$ as determined using an elemental mode of X-ray fluorescence spectrometer. The phase was confirmed through the analysis of powder X-ray diffraction patterns. The raw material for the preparation of lauha bhasma was subjected to normal purification steps by heating the material to red hot condition and immersing in liquids like sesame oil, butter milk, cow's urine, rice gruel, and horse gram decoction [4]. The thermal treatment with each liquid was repeated thrice and was followed by a special purification step in which the intermediate obtained after general purification was heated to a red-hot condition and immersed in Triphala decoction and cow's urine. This was repeated seven times and the solid product is "intermediate after vishesha sodhana."

Triphala decoction was prepared by heating equal quantities each of Terminalia chebula (Chebulic myrobalans), Terminalia bellerica (Beleric myrobalans), and Phyllanthus emblica (Indian gooseberry) with two parts of water and reduced to $1 / 4$ th of the original volume [4]. This Triphala decoction was added to "intermediate after vishesha sodhana" and allowed to dry under sunlight for five days. This process was repeated seven times to yield "intermediate after Bhanupaka" [4].

2.2. Analysis of Plant Extracts. Aqueous extracts of each of the three fruits used in Triphala decoction as well as the Triphala decoction were prepared individually using MilliQ water (Millipore, USA), and analyzed using LC-MS/MS (micrOTOF-QII, Bruker, Germany) to identify speciesspecific compounds, to authenticate the plant used.

\subsection{Electrospray Ionization Mass Spectrometry (ESI-MS/MS).} In order to perform a qualitative analysis of the compounds present in Triphala decoction, each aqueous extract was analysed by LC/ESI/MS using Bruker UHPLC 3000 chromatography coupled to a quadrupole ToF mass selective detector
TABLE 1: Experimental conditions used for LC-MS/MS analysis of Triphala decoction.

\begin{tabular}{|c|c|}
\hline Column & $\begin{array}{l}\mathrm{RP} C 18(100 \mathrm{~mm} \times 3.9 \mathrm{~mm}) \\
\text { internal diameter }=5 \mu \mathrm{m}\end{array}$ \\
\hline Elution & Gradient \\
\hline \multicolumn{2}{|l|}{ Mobile phases } \\
\hline A & Acetonitrile \\
\hline $\mathrm{B}$ & MilliQ water with acetic acid (2\%) \\
\hline \multicolumn{2}{|l|}{ Gradient profile } \\
\hline $0-10 \mathrm{~min}$ & $95 \% \mathrm{~B}$ and $5 \% \mathrm{~A}$ \\
\hline $10-11 \mathrm{~min}$ & $90 \% \mathrm{~B}$ and $10 \% \mathrm{~A}$ \\
\hline $11-20 \mathrm{~min}$ & $80 \% \mathrm{~B}$ and $20 \% \mathrm{~A}$ \\
\hline $20-21 \mathrm{~min}$ & $90 \% \mathrm{~B}$ and $10 \% \mathrm{~A}$ \\
\hline $21 \mathrm{~min}-\mathrm{end}$ of run & $100 \% \mathrm{~A}$ \\
\hline Flow rate & $800 \mu \mathrm{L} / \mathrm{min}$ \\
\hline Detection wavelength & $355 \mathrm{~nm}$ \\
\hline Mass spectra & Negative ion mode \\
\hline Fragmentor voltage $(\mathrm{V})$ & 100 \\
\hline Capillary voltage (V) & 2500 \\
\hline Nebulizer pressure (psi) & 30.5 \\
\hline Drying gas temperature $\left({ }^{\circ} \mathrm{C}\right)$ & 350 \\
\hline$m / z$ scan range & $100-1500$ \\
\hline Gas flow (L/min) & 6.0 \\
\hline Collision energy (eV) & 8 \\
\hline Retention Factor (Vpp) & 150 \\
\hline Transfer time $(\mu \mathrm{s})$ & 80 \\
\hline Pre pulse storage $(\mu \mathrm{s})$ & 10 \\
\hline
\end{tabular}

(micrOTOF-QII). The operating conditions are shown in the Table 1.

2.4. Spectroscopic and Powder Diffraction Analyses. The Fourier transform infrared (FTIR) spectra of intermediates were recorded between 4000 and $400 \mathrm{~cm}^{-1}$ in an FTIR spectrometer (Spectrum 100, Perkin Elmer, USA) by pelletizing them with $\mathrm{KBr}$ using a hydraulic press. For the quantitative determination of carbon content, about $2 \mathrm{mg}$ of each sample was weighed using a microbalance (Sartorius, USA) and analyzed in a CHNS/O analyzer (Series II 2400, Perkin Elmer, USA). The powder X-ray diffraction patterns were recorded using an X-ray diffractometer (D8 Focus, Bruker, Germany), by irradiating with $\mathrm{Cu}-\mathrm{K}_{\alpha}$ radiation from $10^{\circ}$ to $60^{\circ}(2 \theta)$ with a step size of $0.01^{\circ}$.

2.5. Thermal Analysis. The thermogravimetric analysis of samples was performed using a simultaneous TG-DTA instrument (SDT Q600, TA Instruments, USA). An accurately weighed quantity of sample was taken in an aluminum cup and heated in nitrogen atmosphere by maintaining a rate of $10^{\circ} \mathrm{C} /$ minute. 


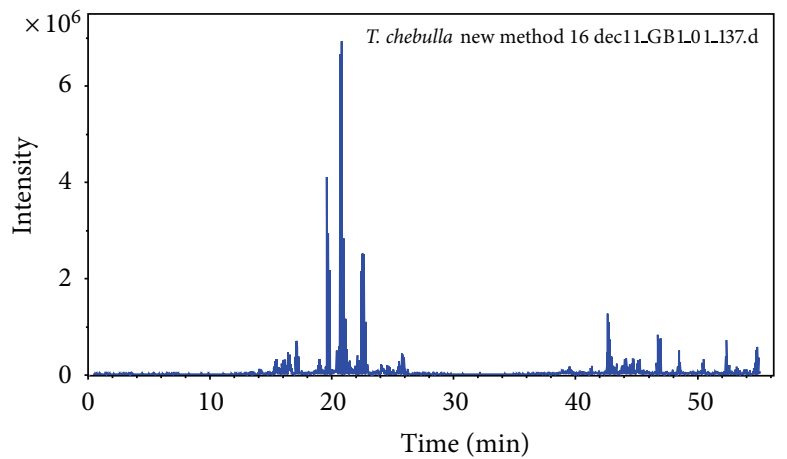

(a)

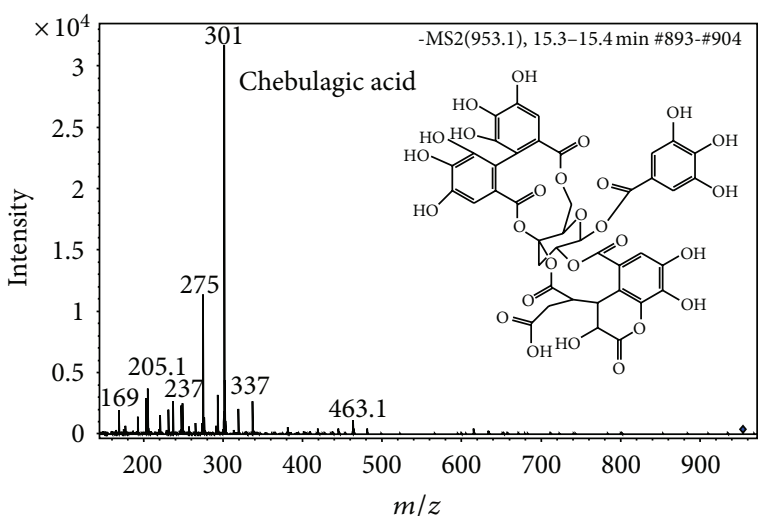

(b)

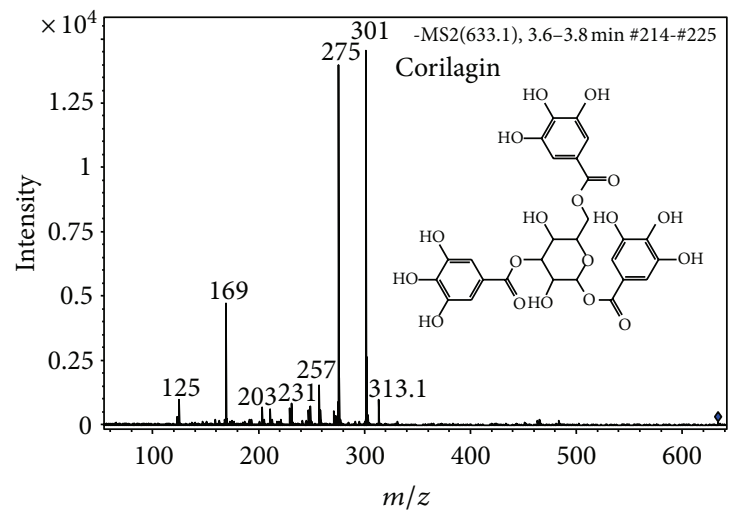

(c)

Figure 1: Chromatograms obtained from reversed-phase LC-ESI-QTOF-MS analysis of Terminalia chebula extract. (a) Total ion chromatogram (QTOF MS); (b) and inset in (b) corresponding to $\mathrm{m} / z$ for the most intense peaks of MS/MS spectrum pattern of Chebulagic acid; (c) corresponding to $m / z$ for the most intense peaks view of MS/MS spectrum pattern of Corilagin.

\section{Results and Discussions}

\subsection{Constituents of Triphala Decoction}

3.1.1. Terminalia chebula-Key Constituents and Therapeutic Applications. Terminalia chebula contains eighteen amino acids and the chief constituents of this fruit are tannic acid, chebulinic acid, chebulagic acid, gallic acid, corilagin, and so forth $[5,6]$. Further, it possesses antifungal and antibacterial activity and inhibits the growth of $E$. coli, which causes urinary tract infection [7]. This fruit is used to treat chronic ulcers, leucorrhoea, pyorrhea, and fungal infections of the skin. The fruit increases the frequency of stools and evacuates the bowel completely and hence is an effective laxative [8]. In addition, Terminalia chebula delays symptoms of aging, imparts longevity, immunity, and resistance against diseases. Chebulagic acid and corilagin were among various other secondary metabolites identified for which LC MS/MS data is presented in Figure 1.

3.1.2. Terminalia bellerica-Key Constituents and Therapeutic Applications. The chief constituents of this fruit are beleric acid, $\beta$-sitosterol, saponin glycosides, gallic acid, ellagic acid, chebulagic acid, lignans, and so forth [9]. It is antiasthmatic and antispasmodic and possesses antitussive activity and is used as an expectorant $[9,10]$. This fruit is used to relieve excessive thirst, nausea, and vomiting and to manage cough and infectious conditions [10, 11]. It is a natural sedative, which is used in the treatment of insomnia, and it is also known to be good for eyes and rejuvenates hair [11]. The fruit reduces levels of lipids in hypercholesterolemia and significantly decreases liver and heart lipids [12]. Most importantly, Terminalia belerica is a well-known laxative, which softens feces in rectum $[13,14]$. This fruit has been reported to possess antimalarial and antioxidant activity [15]. Ellagic acid was one among the various other secondary metabolites identified as shown in Figure 2.

3.1.3. Phyllanthus emblica-Key Constituents and Their Applications. Phyllanthus emblica is a rich source of vitamin C and possesses antifungal [16], antibacterial [16], antiviral [17], diuretic, and antioxidant properties $[9,18]$. It is also a rejuvenating agent [19] and chelates copper and iron. Since it has free radical quenching properties, it reduces UVinduced erythema [20]. It cures diarrhea [21], mouth ulcers $[21,22]$, and nausea [16], dental and respiratory problems [23]. Punicalagin was one among the various other secondary metabolites identified as shown in Figure 3. 


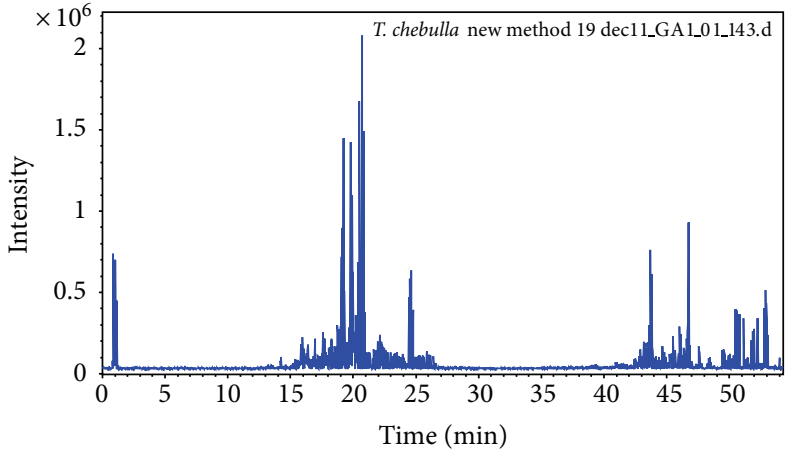

(a)

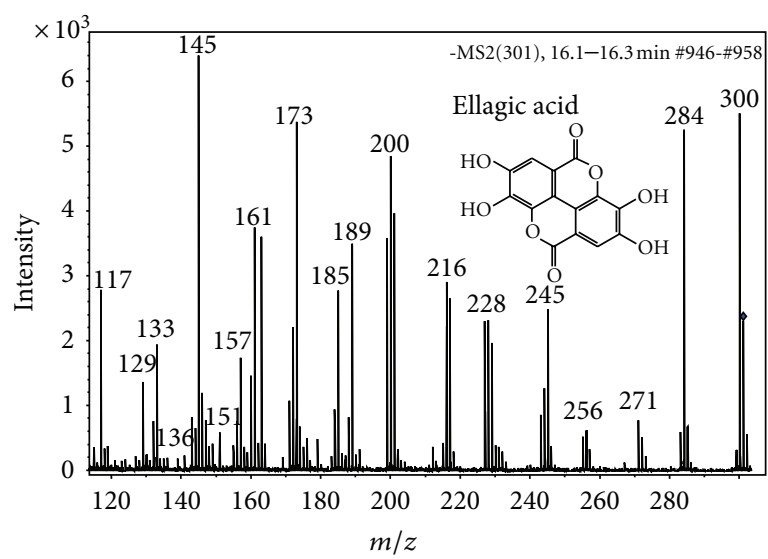

(b)

FIGURE 2: Chromatograms obtained from reversed-phase LC-ESI-QTOF-MS analysis of Terminalia belerica extract. (a) Total ion chromatogram (QTOF MS); (b) corresponding to $\mathrm{m} / \mathrm{z}$ for the most intense peaks view of MS/MS spectrum pattern of Ellagic acid.

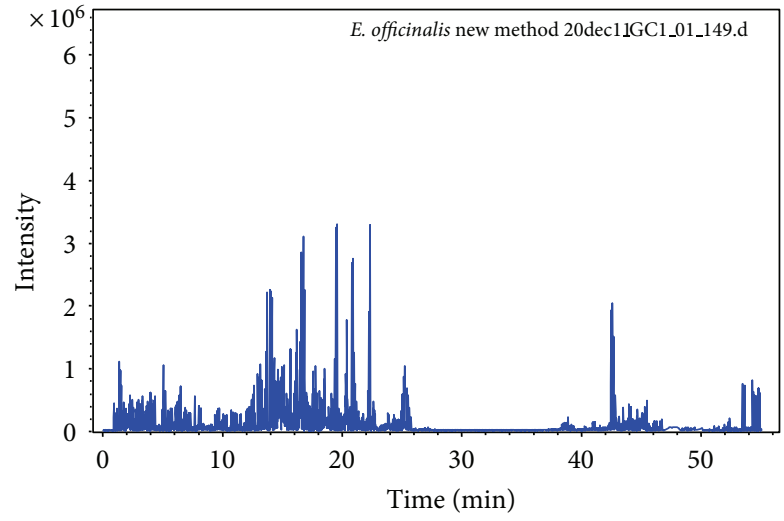

(a)

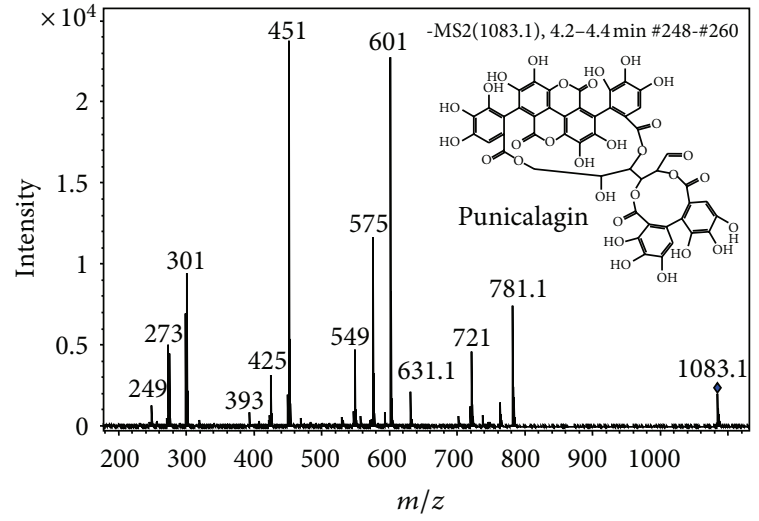

(b)

FIGURE 3: Chromatograms obtained from reversed-phase LC-ESI-QTOF-MS analysis of Phyllanthus emblica extract. (a) Total ion chromatogram (QTOF MS); (b) corresponding to $\mathrm{m} / \mathrm{z}$ for the most intense peaks of MS/MS spectrum pattern of punicalagin.

These three fruits are collectively known as Triphala and their aqueous extract is a rejuvenating formula, which is applied in Ayurveda to treat intestinal disorders such as inflammation, infection, diarrhea, and constipation [24]. The LC MS/MS spectra of Triphala decoction is shown in Figure 4. It may be observed from Figure 4 that the important constituents of each of the fruit were present in the Triphala decoction.

3.2. Intermediate after Vishesha Sodhana. The percentage of carbon, hydrogen, and nitrogen in the "intermediate after vishesha sodhana" and "intermediate after Bhanupaka" were determined to identify the chemical transformations that occur during Bhanupaka. The analyses (Table 2) show that the intermediate after vishesha sodhana contains a very low percentage of carbon and hydrogen.

From the powder X-ray diffraction patterns (Figure 5), this intermediate was identified to be crystalline $\mathrm{Fe}_{2} \mathrm{O}_{3}$.
TABLE 2: Carbon, hydrogen and nitrogen contents in intermediate after vishesha sodhana and the intermediate after Bhanupaka.

\begin{tabular}{lccc}
\hline & Carbon (\%) & Hydrogen (\%) & Nitrogen (\%) \\
\hline $\begin{array}{l}\text { Intermediate after } \\
\text { vishesha sodhana }\end{array}$ & $1.07 \pm 0.09$ & $0.12 \pm 0.07$ & $0.17 \pm 0.23$ \\
$\begin{array}{l}\text { Intermediate after } \\
\text { Bhanupaka }\end{array}$ & $9.98 \pm 0.49$ & $0.87 \pm 0.1$ & $0.12 \pm 0.1$ \\
\hline
\end{tabular}

There were no characteristic absorption bands in the region of $1000-3000 \mathrm{~cm}^{-1}$, indicating the absence of organic moieties (Figure 6).

Thermogravimetric analysis of intermediate after vishesha sodhana showed a gradual mass change of about $9.7 \%$ only over a temperature range of $50-1000^{\circ} \mathrm{C}$, indicating that the material did not undergo appreciable changes in its chemical nature and hence the intermediate obtained after vishesha sodhana is $\mathrm{Fe}_{2} \mathrm{O}_{3}$. 


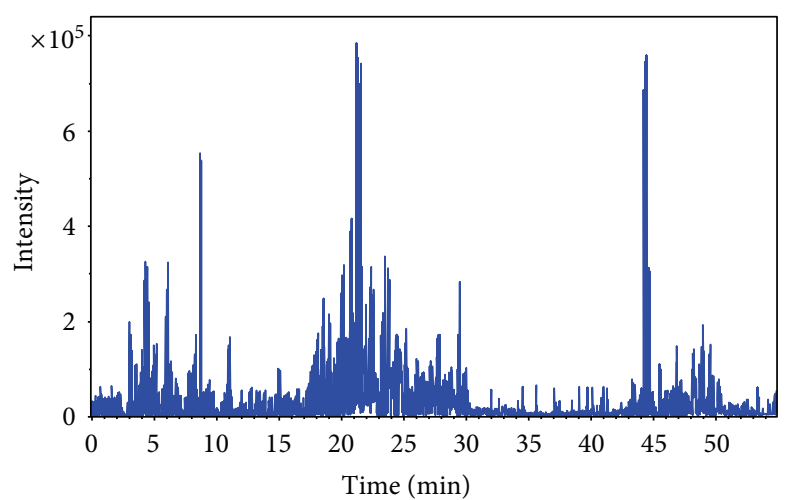

(a)

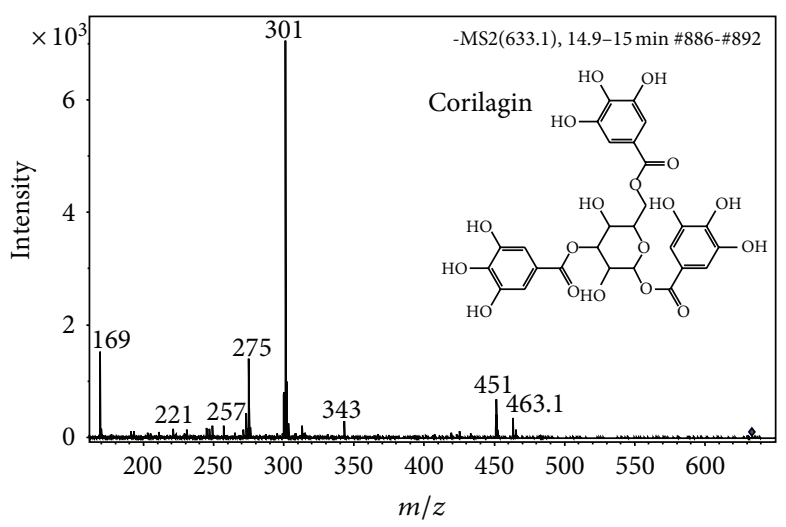

(c)

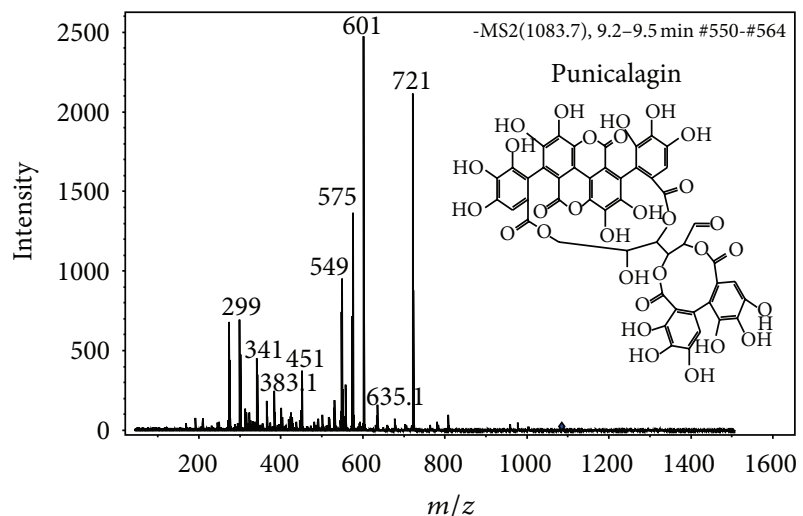

(b)

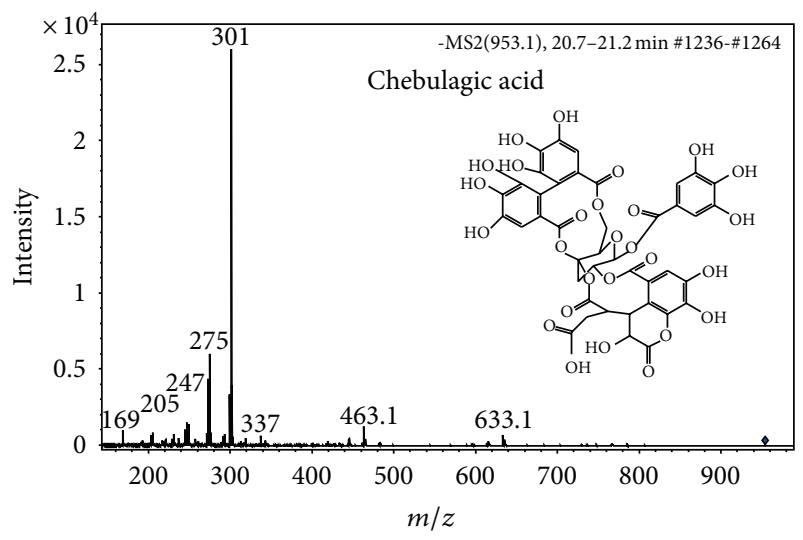

(d)

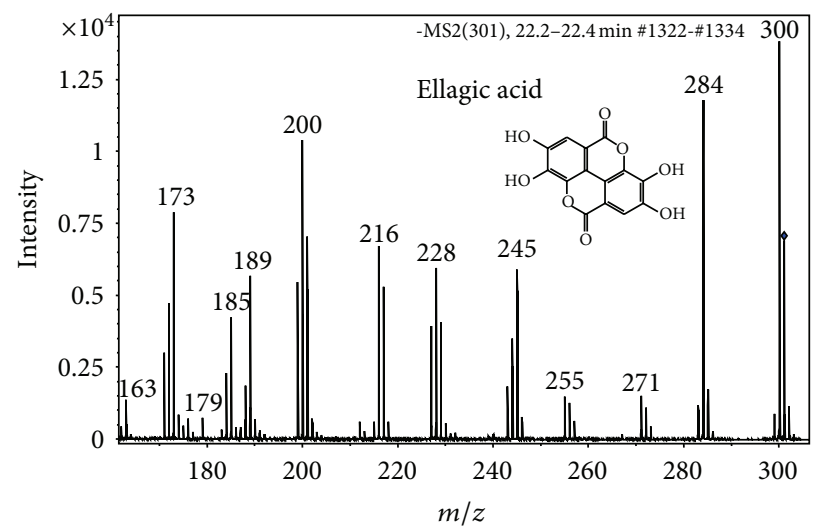

(e)

Figure 4: Chromatograms obtained from reversed-phase LC-ESI-QTOF-MS analysis of Triphala decoction. (a) Total ion chromatogram (QTOF MS); (b) corresponding to $\mathrm{m} / z$ for the most intense peaks of MS/MS spectrum pattern of punicalagin; (c) corresponding to $\mathrm{m} / \mathrm{z}$ for the most intense peaks of MS/MS spectrum pattern of corilagin; (d) corresponding to $\mathrm{m} / z$ for the most intense peaks of MS/MS spectrum pattern of chebulagic acid; (e) corresponding to $\mathrm{m} / z$ for the most intense peaks of MS/MS spectrum pattern of ellagic acid.

3.3. Intermediate after Bhanupaka. The $\mathrm{C}, \mathrm{H}$, and $\mathrm{N}$ analyses of intermediate after Bhanupaka shows the presence of a higher carbon content to the extent of $10 \%$ against $1 \%$ for the intermediate after vishesha sodhana. The intermediate after Bhanupaka was washed several times with water for the purpose of analysis. Hence, the higher carbon content cannot be attributed to the surface adsorption of contents of Triphala decoction. Further, the FTIR spectrum (Figure 6) shows characteristic absorption bands for C-H stretching (2940$\left.2980 \mathrm{~cm}^{-1}\right)$ and $\mathrm{C}=\mathrm{O}\left(1630-1680 \mathrm{~cm}^{-1}\right)$ and a broad hydrogen bonded $-\mathrm{OH}$ band around $3450 \mathrm{~cm}^{-1}$. These bands were absent in the intermediate after vishesha sodhana. Hence, these absorption bands indicate the formation of a complex between iron and organic constituents in Triphala decoction. 


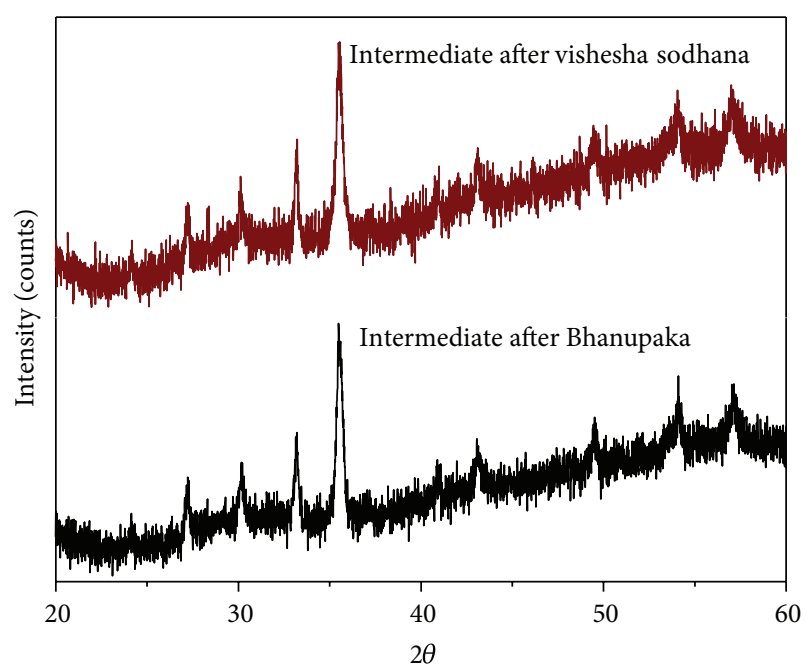

Figure 5: Powder X-ray diffractogram of intermediate after vishesha sodhana and the intermediate after Bhanupaka.

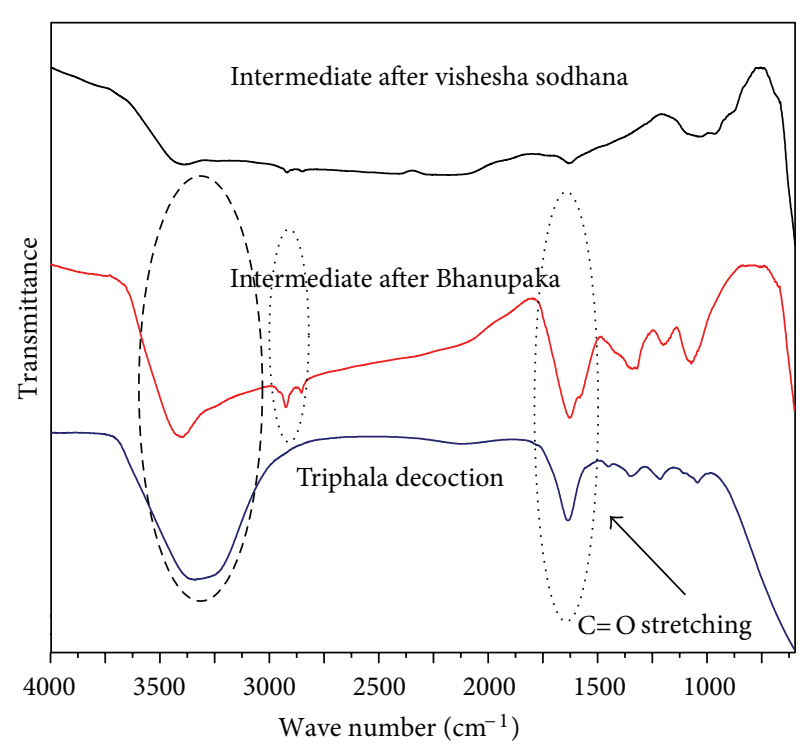

FIGURE 6: FTIR spectra of intermediate after vishesha sodhana and the intermediate after Bhanupaka.

It is difficult to ascertain the exact chemical identity of this intermediate owing to the presence of several organic components in Triphala decoction that can coordinate with iron. The shift in absorption bands in the wave number range of $1000-1400 \mathrm{~cm}^{-1}$ broadening of hydrogen bonded $-\mathrm{OH}$ absorption band and $v_{\mathrm{C}-\mathrm{O}}$ for intermediate after Bhanupaka compared to Triphala decoction may be attributed to the coordination of constituents of Triphala decoction with iron (Figure 6). The sharp X-ray diffraction peaks (Figure 5) corresponding to $\mathrm{Fe}_{2} \mathrm{O}_{3}$ indicate the presence of $\mathrm{Fe}_{2} \mathrm{O}_{3}$ also. This could probably be attributed to the fact that the reaction between intermediate and Triphala decoction proceeds from the outer surface following a shrinking-core model. As a result of the repeated treatment with Triphala decoction under sunlight, the slow reaction between intermediate after vishesha sodhana and organic constituents proceeds from the outer surface towards the central region, which remains as crystalline $\mathrm{Fe}_{2} \mathrm{O}_{3}$. Substantial nanoscale features on the intermediate after vishesha sodhana would have resulted in increased surface area and better interaction between fluid phase (Triphala decoction) and the solid (intermediate after vishesha sodhana) [25-28]. Thermogravimetric analysis of intermediate after Bhanupaka in nitrogen atmosphere showed a weight loss of $11.95 \%$ in the temperature range of $740-840^{\circ} \mathrm{C}$, which could be attributed to the decomposition of the complex. This weight loss correlates reasonably with the mass percentage of carbon $(\sim 10 \%)$ in the intermediate after Bhanupaka.

3.4. Role of Sunlight during Bhanupaka. It has been widely established that the metallic iron $\left(\mathrm{Fe}^{0}\right)$ is toxic [29]. Hence, iron supplements should contain iron in the form of complex. The UV radiation present in the sunlight reduces the oxidation state of iron in presence of vitamin $\mathrm{C}$ present in the Triphala decoction thereby improving the bioavailability [30]. The capability of constituents to absorb UV radiation is also confirmed by the electronic spectra shown in Figure 7.

\subsection{Role of Triphala Extract in Chemical Transformation-} Formation of Chelates. After administration of iron complex, enzymes present in the body cleave the chelated iron and liberating iron for absorption to produce hemoglobin. The organic moiety that forms the chelate must be nontoxic, should be easily eliminated by the body, and may provide some synergistic therapeutic effects. This forms the rationale for the choice of these three fruits, namely, Indian gooseberry, Chebulic myrobalans, and Beleric myrobalans in the preparation of Triphala decoction.

Corilagin, chebulagic acid, and ellagic acid, which are the key constituents of Triphala decoction, are known to form chelates with iron to preserve the same in a biocompatible form. Moreover, these organic ligands will be converted to gallic acid, which possesses hepatoprotective activity [12].

Usually, when anemic patients take allopathic iron tablets and other iron preparations, they suffer from side effects such as constipation, nausea, and vomiting. The organic moieties present in these fruits possess laxative properties and hence may prevent constipation [8]. Vitamin C, the major ingredient in Indian gooseberry, is not only a reducing agent, but also an antioxidant. Thus, these fruits are useful not only to keep iron in a stable complex form but also other ingredients possess important physiological activities.

3.6. Role of Triphala Decoction as an Antimicrobial Agent. During the preparation of lauha bhasma, intermediates obtained after each stage are stored for further processing. As the intermediates are obtained by treating with several aqueous-based liquids, fungal growth during storage may render them unsuitable for further processing. Similarly, the finished bhasma are stored for longer duration of time and are considered to be nonexpiring. Hence, the antimicrobial 


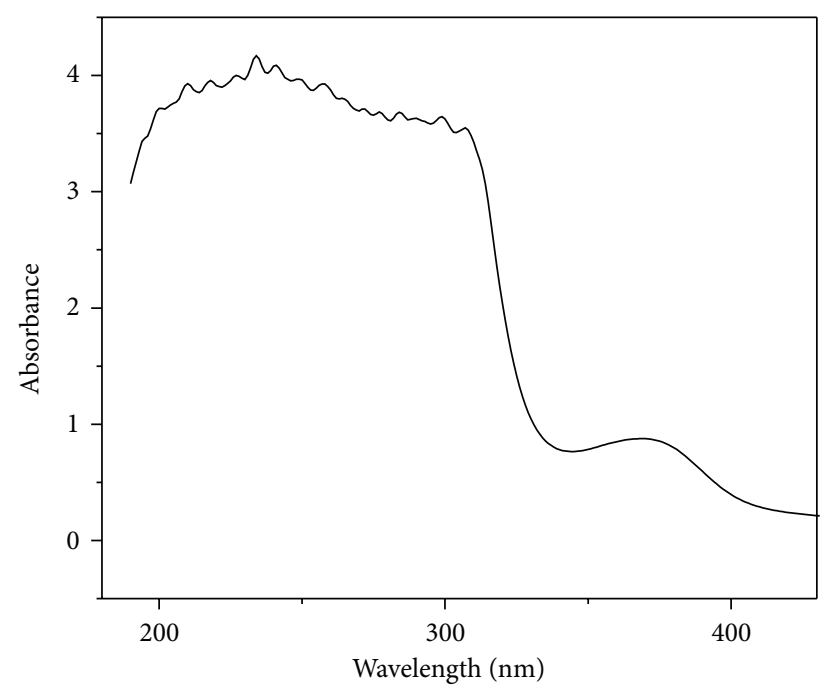

FIgURE 7: Electronic spectrum of Triphala decoction.

activity of Triphala decoctionmay helps in the storage of intermediates and finished bhasma.

\section{Conclusions}

Triphala decoction is used during Bhanupaka, a green step used in the preparation of lauha bhasma-an iron based herbometallic preparation. The key constituents of Triphala decoction were identified using LC-MS/MS. The intermediates before and after Bhanupaka have been characterized to ascertain their chemical identity thereby facilitating the understanding of the process. Our results show that constituents of Triphala decoction form coordination compounds with iron oxide, by a slow reaction under prolonged exposure to UV radiation present in the sunlight. The useful ingredients of Triphala decoction are expected to be available to body upon the consumption of these medicines, thereby imparting their therapeutic properties.

\section{Acknowledgments}

The authors gratefully acknowledge the funding provided by the Drugs and Pharmaceutical Research (VID\&P/267/08/09/TDT), Department of Science \& Technology (DST), India, and SASTRA University for this work. They also acknowledge the funding from the Nano Mission Council (SR/NM/PG-16/2007), DST, India, for the XRD.

\section{References}

[1] V. B. Dash and A. M. M. Junius, A Hand Book of Ayurveda, Concept Publishing Company, New Delhi, India, 2003.

[2] K. Balaji, P. Brindha, K. Sridharan, K. Uma Maheswari, S. Swaminathan, and K. S. Rajan, "Elucidation of a core-shell model for lauha bhasma through physico-chemical characterization," International Journal of Pharmacy and Pharmaceutical Sciences, vol. 4, no. 2, pp. 644-649, 2012.
[3] P. K. Sarkar, S. Das, and P. K. Prajapati, "Ancient concept of metal pharmacology based on Ayurvedic literature," Ancient Science of Life, vol. 94, no. 4, pp. 1-6, 2010.

[4] K. Balaji, P. Brindha, K. Sridharan, K. Uma Maheswari, S. Swaminathan, and K. S. Rajan, "Scientific validation of the different purification steps involved in the preparation of an Indian Ayurvedic medicine, lauha bhasma," Journal of Ethnopharmacology, vol. 142, no. 1, pp. 98-104, 2012.

[5] R. R. Chattopadhyay, S. K. Bhattacharyya, C. Medda, S. Chanda, and A. Bag, "A comparative evaluation of antibacterial potential of some plants used in Indian traditional medicine for the treatment of microbial infections," Brazilian Archives of Biology and Technology, vol. 52, no. 5, pp. 1123-1128, 2009.

[6] J. H. Park, H. S. Joo, K. Y. Yoo, B. N. Shin, I. H. Kim, C. H. Lee et al., "Extract from Terminalia chebula seeds protect against experimental ischemic neuronal damage via maintaining SODs and BDNF levels," Neurochemical Research, vol. 36, no. 11, pp. 2043-2050, 2011.

[7] A. Sharma, R. Verma, and P. Ramtek, "Antibacterial activity of some medicinal plants used by tribals against uti causing pathogens," World Applied Sciences Journal, vol. 7, no. 3, pp. 332$339,2009$.

[8] A. Sharma, S. Chandraker, V. K. Patel, and P. Ramteke, "Antibacterial activity of medicinal plants against pathogens causing complicated urinary tract infections," Indian Journal of Pharmaceutical Sciences, vol. 71, no. 2, pp. 136-139, 2009.

[9] A. S. Saroya and A. S., Herbalism, Phytochemistry and Ethnopharmacology, CRC Press, Boca Raton, Fla, USA, 2011.

[10] R. Prasad, R. D. Lawania, Manvi, and R. Gupta, "Role of herbs in the management of asthma," Pharmacognosy Reviews, vol. 3, no. 6, pp. 247-258, 2009.

[11] A. K. Gautam and R. Bhadauria, "Fungal contamination of few common stored herbal fruit samples," The Internet Journal of Nutrition and Wellness, vol. 8, no. 1, p. 4, 2009.

[12] K. K. Anand, B. Singh, A. K. Saxena, B. K. Chandan, V. N. Gupta, and V. Bhardwaj, "3,4,5-trihydroxy benzoic acid (gallic acid), the hepatoprotective principle in the fruits of Terminalia belerica-bioassay guided activity," Pharmacological Research, vol. 36, no. 4, pp. 315-321, 1997.

[13] N. S. Chauhan, Medicinal and Aromatic Plants of Himachal Pradesh, Indus Publishing Company, New Delhi, India, 1999.

[14] N. Gargi and D. Bratati, "Acetylcholinesterase inhibitory activity of Terminaliachebula, Terminaliabellerica and Emblica officinalis and some phenolic compounds," International Journal of Pharmacy and Pharmaceutical Sciences, vol. 3, no. 3, pp. 121-124, 2011.

[15] K. Pinmai, S. Chunlaratthanabhorn, C. Ngamkitidechakul, N. Soonthornchareon, and C. Hahnvajanawong, "Synergistic growth inhibitory effects of Phyllanthus emblica and Terminalia bellerica extracts with conventional cytotoxic agents: doxorubicin and cisplatin against human hepatocellular carcinoma and lung cancer cells," World Journal of Gastroenterology, vol. 14, no. 10, pp. 1491-1497, 2008.

[16] L. Treadway, "Amla Traditional food and medicine," HerbalGram, vol. 31, pp. 26-31, 1994.

[17] D. A. Dhale and U. P. Mogle, "Phytochemical screening and antibacterial activity of Phyllanthus emblica (L.)," Science Research Reporter, vol. 1, no. 3, pp. 138-142, 2011.

[18] A. Bhattacharya, A. Chatterjee, S. Ghosal, and S. K. Bhattacharya, "Antioxidant activity of active tannoid principles of Emblica officinalis (amla)," Indian Journal of Experimental Biology, vol. 37, no. 7, pp. 676-680, 1999. 
[19] S. A. Qureshi, W. Asad, and V. Sultana, "The effect of Phyllantus emblica Linn on type-II diabetes, triglycerides and liver-specific enzyme," Pakistan Journal of Nutrition, vol. 8, no. 2, pp. 125-128, 2009.

[20] S. S. Nair, M. Mathew, and K. Sreena, "Evaluation of skin irritation of herbal antioxidant cream," Asian Journal of Biochemical and Pharmaceutical Research, vol. 2, no. 3, pp. 184-189, 2012.

[21] K. P. Srivasuki, "Nutritional and Health care benefits of Amla," Journal of Pharmacognosy, vol. 3, no. 2, pp. 147-151, 2012.

[22] A. Kumar, A. Singh, and J. Dora, "Essentials perspectives for Emblica officinalis," International Journal of Pharmaceutical and Chemical Sciences, vol. 1, no. 1, pp. 11-18, 2012.

[23] S. S. Patel and R. K. Goyal, "Emblica officinalis Geart.: a comprehensive review on phytochemistry, pharmacology and ethnomedicinal uses," Research Journal of Medicinal Plant, vol. 6, no. 1, pp. 6-16, 2012.

[24] M. Gupta, "Therapeutic uses of the polyherbal drug Triphala in Geriatric diseases," International Journal of Pharma and Bio Sciences, vol. 1, no. 2, pp. 1-13, 2010.

[25] K. S. Rajan, K. Dhasandhan, S. N. Srivastava, and B. Pitchumani, "Studies on gas-solid heat transfer during pneumatic conveying," International Journal of Heat and Mass Transfer, vol. 51, no. 11-12, pp. 2801-2813, 2008.

[26] K. S. Rajan, B. Pitchumani, S. N. Srivastava, and B. Mohanty, "Two-dimensional simulation of gas-solid heat transfer in pneumatic conveying," International Journal of Heat and Mass Transfer, vol. 50, no. 5-6, pp. 967-976, 2007.

[27] K. S. Rajan, S. N. Srivastava, B. Pitchumani, and B. Mohanty, "Simulation of gas-solid heat transfer during pneumatic conveying: use of multiple gas inlets along the duct," International Communications in Heat and Mass Transfer, vol. 33, no. 10, pp. 1234-1242, 2006.

[28] K. S. Rajan, S. N. Srivastava, B. Pitchumani, and B. Mohanty, "Simulation of countercurrent gas-solid heat exchanger: effect of solid loading ratio and particle size," Applied Thermal Engineering, vol. 27, no. 8-9, pp. 1345-1351, 2007.

[29] G. Papanikolaou and K. Pantopoulos, "Iron metabolism and toxicity," Toxicology and Applied Pharmacology, vol. 202, no. 2, pp. 199-211, 2005.

[30] H. D. Takagi, N. Kagayama, M. Matsumoto, T. Tarumi, and S. Funahashi, "Mechanistic study of oxidation reactions of hydroquinone, catechol, and L-ascorbic acid by dicyanobis(1,10phenanthroline)iron(III) in dimethyl sulfoxide," Journal of Molecular Liquids, vol. 65-66, pp. 277-280, 1995. 

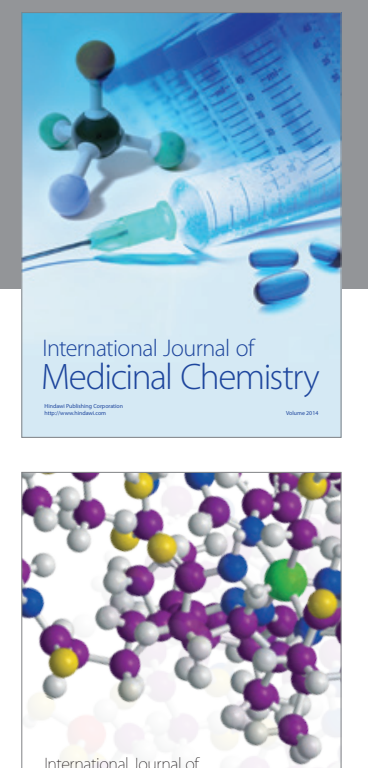

\section{Carbohydrate} Chemistry

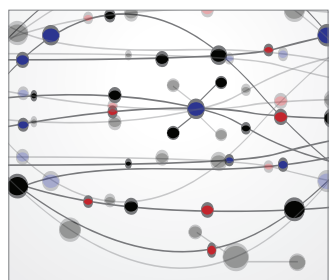

The Scientific World Journal
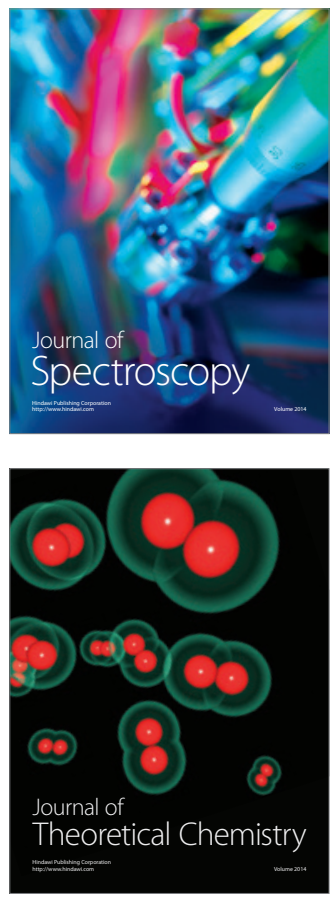
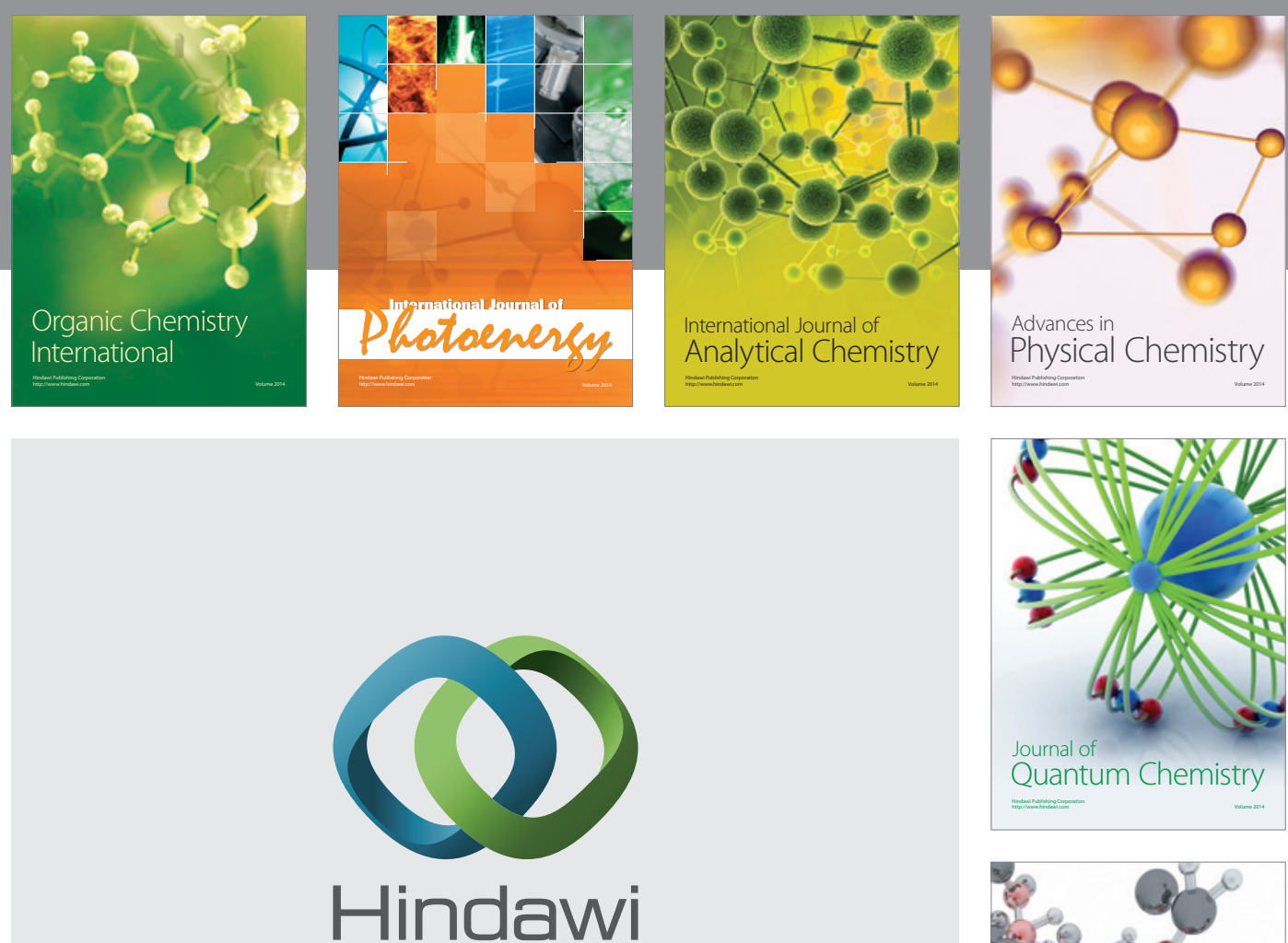

Submit your manuscripts at

http://www.hindawi.com

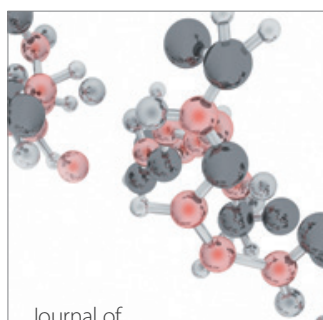

Analytical Methods

in Chemistry

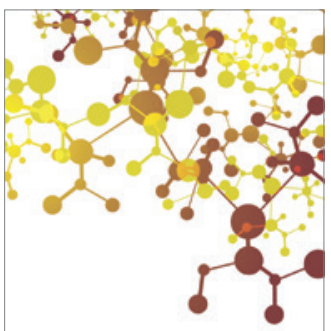

Journal of

Applied Chemistry

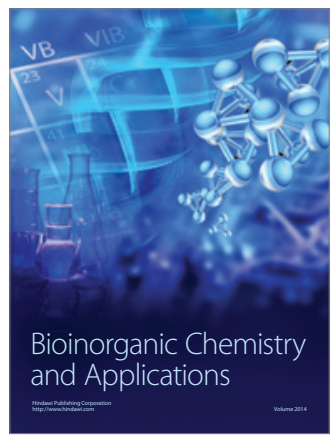

Inorganic Chemistry
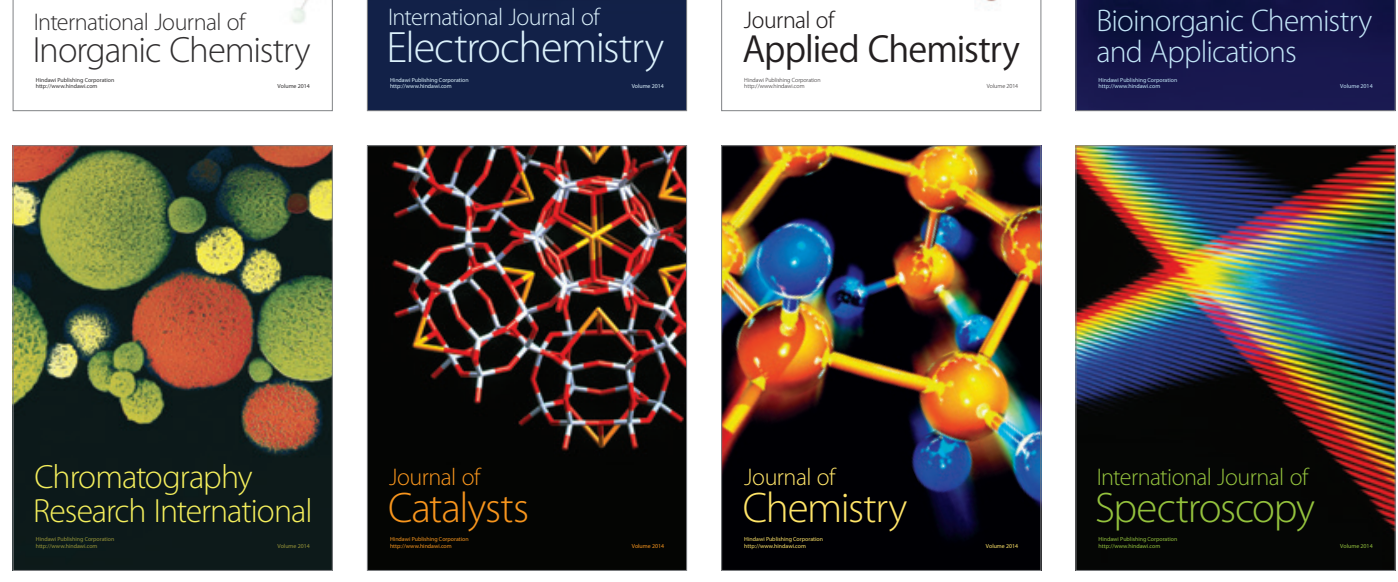